\title{
Selective Expression of ErbB4 in Interneurons, But Not Pyramidal Cells, of the Rodent Hippocampus
}

\author{
Detlef Vullhorst, ${ }^{1}$ Jörg Neddens, ${ }^{1}$ Irina Karavanova, ${ }^{1}$ Ludovic Tricoire, ${ }^{2}$ Ronald S. Petralia, ${ }^{3}$ Chris J. McBain, ${ }^{2}$ \\ and Andres Buonanno ${ }^{1}$ \\ ${ }^{1}$ Section on Molecular Neurobiology and ${ }^{2}$ Laboratory of Cellular and Molecular Neurophysiology, Eunice Shriver Kennedy National Institute of Child \\ Health and Human Development, and ${ }^{3}$ Laboratory of Neurochemistry, National Institute on Deafness and other Communication Disorders, Bethesda, \\ Maryland 20892
}

\begin{abstract}
NRG1 and ERBB4 have emerged as some of the most reproducible schizophrenia risk genes. Moreover, the Neuregulin (NRG)/ErbB4 signaling pathway has been implicated in dendritic spine morphogenesis, glutamatergic synaptic plasticity, and neural network control. However, despite much attention this pathway and its effects on pyramidal cells have received recently, the presence of ErbB4 in these cells is still controversial. As knowledge of the precise locus of receptor expression is crucial to delineating the mechanisms by which NRG signaling elicits its diverse physiological effects, we have undertaken a thorough analysis of ErbB4 distribution in the CA1 area of the rodent hippocampus using newly generated rabbit monoclonal antibodies and ErbB4-mutant mice as negative controls. We detected ErbB4 immunoreactivity in GABAergic interneurons but not in pyramidal neurons, a finding that was further corroborated by the lack of ErbB4 mRNA in electrophysiologically identified pyramidal neurons as determined by single-cell reverse transcription-PCR. Contrary to some previous reports, we also did not detect processed ErbB4 fragments or nuclear ErbB4 immunoreactivity. Ultrastructural analysis in CA1 interneurons using immunoelectron microscopy revealed abundant ErbB4 expression in the somatodendritic compartment in which it accumulates at, and adjacent to, glutamatergic postsynaptic sites. In contrast, we found no evidence for presynaptic expression in cultured GAD67-positive hippocampal interneurons and in CA1 basket cell terminals. Our findings identify ErbB4-expressing interneurons, but not pyramidal neurons, as a primary target of NRG signaling in the hippocampus and, furthermore, implicate ErbB4 as a selective marker for glutamatergic synapses on inhibitory interneurons.
\end{abstract}

\section{Introduction}

The receptor tyrosine kinase ErbB4 binds members of the Neuregulin (NRG) and epidermal growth factor (EGF) [betacellulin, HB-EGF (heparin-binding EGF), epiregulin] families of trophic and differentiation factors to regulate a diverse array of neuronal processes, including migration, differentiation, neurotransmission, and synaptic plasticity (for review, see Buonanno and Fischbach, 2001; Mei and Xiong, 2008). ErbB4 is expressed in the developing and adult cerebral cortex, and represents the major NRG receptor in central neurons (Lai and Lemke, 1991; Steiner et al., 1999; Gerecke et al., 2001; Yau et al., 2003; Fox and Kornblum, 2005). At Schaffer collateral-to-CA1 (SC-CA1) glutamatergic synapses in the adult hippocampus, NRG-1/ErbB signaling inhibits and reverses (depotentiates) long-term potentiation (LTP) (Huang et al., 2000; Kwon et al., 2005; Bjarnadottir

Received May 21, 2009; revised July 29, 2009; accepted Aug. 13, 2009.

This work was supported by the National Institute of Child Health and Human Development (NICHD) intramural program (D.V., J.N., I.K., L.T., C.J.M., A.B.) and the National Institute on Deafness and Other Communication Disorders intramural program (R.S.P.). We thank Dr. Ya-Xian Wang for help with immunoelectron microscopy, Dr. Z. Sheng for the SNPH $\Delta$ MT-GFP construct, and V. Schram and C. Smith from the NICHD and National Institute of Neurological Disorders and Stroke microscopy core facilities for expert assistance.

Correspondence should be addressed to Dr. Andres Buonanno, Section on Molecular Neurobiology, Building 35, Room 2C-1000, 35 Lincoln Drive, National Institutes of Health, Bethesda, MD 20892-3714. E-mail: buonanno@mail.nih.gov.

D01:10.1523/JNEUROSCI.2454-09.2009

Copyright $\odot 2009$ Society for Neuroscience $\quad 0270-6474 / 09 / 2912255-10 \$ 15.00 / 0$ et al., 2007). ErbB receptor activation acutely triggers dopamine release in the hippocampus, and LTP depotentiation by NRG-1 depends on the activation of $\mathrm{D}_{4}$ dopamine receptors to reduce synaptic levels of AMPA-type ionotropic glutamate receptors (Kwon et al., 2008). Conversely, LTP is enhanced in ErbB4deficient mice (Pitcher et al., 2008). These studies suggest that NRG-1/ErbB4 signaling is involved in the homeostatic control of glutamatergic plasticity in the adult hippocampus, at least in part via recruitment of a dopaminergic signaling pathway.

In addition to its effects on glutamatergic plasticity of CA1 pyramidal neurons, other studies suggest an important role of ErbB signaling for GABAergic function in the adult cortex. In CA3, NRG-1/ErbB4 signaling potently increases the power of kainate-induced gamma oscillations, suggesting that ErbB4 is involved in the synchronization of CA3 pyramidal cell firing by local parvalbumin (PV)-expressing basket cell interneurons, many of which express ErbB4 (Fisahn et al., 2009). Consistent with this finding, both the number of PV-interneurons and the power of kainate-induced gamma oscillations are reduced in ErbB4-knock-out (KO) mice (Fisahn et al., 2009). In the mouse prefrontal cortex, NRG-1 signaling via ErbB4 was shown to modulate GABAergic transmission by augmenting depolarizationinduced transmitter release (Woo et al., 2007).

The primary cellular and subcellular locus of ErbB4 signaling that underlies the regulation of plasticity at SC-CA1 synapses has not been identified. In situ hybridization studies in the adult ro- 
dent and monkey cortex have consistently demonstrated scattered ErbB4 mRNA distribution indicative of expression in interneurons (Lai and Lemke, 1991; Steiner et al., 1999; Huang et al., 2000; Gerecke et al., 2001; Fox and Kornblum, 2005; Thompson et al., 2007). Consistent with these findings, most immunofluorescence analyses identified strong ErbB4 immunoreactivity (IR) in GABAergic interneurons in dissociated hippocampal neuron cultures and in the cerebral cortex (Garcia et al., 2000; Huang et al., 2000; Gerecke et al., 2001; Yau et al., 2003; Longart et al., 2007). In contrast, the presence of ErbB4 in pyramidal neurons has been a matter of debate. Several histological studies reported ErbB4-IR in pyramidal neurons in the rodent and monkey cortex (Gerecke et al., 2001; Ma et al., 2003; Mechawar et al., 2007; Thompson et al., 2007), but these findings are at variance with the distribution of ErbB4 mRNA, as noted by some (Gerecke et al., 2001; Thompson et al., 2007). Because of the rapidly growing number of studies linking NRG-1/ErbB signaling to the modulation of pyramidal neuron properties, such as dendritic spine morphology (Li et al., 2007; Chen et al., 2008; Barros et al., 2009), glutamate receptor trafficking (Gu et al., 2005), and synaptic plasticity (Huang et al., 2000; Kwon et al., 2005, 2008; Bjarnadottir et al., 2007; Pitcher et al., 2008), it is imperative to resolve this apparent inconsistency and to determine whether ErbB4 activation modulates pyramidal neurons in a cell-autonomous manner or via a local circuit. Toward this end, we present here a detailed analysis of the cellular and subcellular distribution of ErbB4 in the rodent CA1 area using newly developed rabbit monoclonal antibodies against ErbB4. Our data implicate glutamatergic synapses onto GABAergic interneurons as a primary target of NRG/ErbB4 signaling in the adult CA1, a finding that has important functional implications for our understanding of NRG effects on glutamatergic transmission and plasticity, and its involvement in the pathophysiology underlying schizophrenia.

\section{Materials and Methods}

Animals. New Zealand White rabbits were used to raise the parental polyclonal antiserum against ErbB4 and to derive the hybridoma cell lines. Adult C57BL/6J wild-type and ErbB4-KO mice, as well as Sprague Dawley rats, were used to prepare neocortical or hippocampal extracts for Western blotting and immunoprecipitation (IP), and to cut sections for immunofluorescence and immunoelectron histology. Fetuses from embryonic day 19 (E19) Sprague Dawley rats, E18 C57BL/6J wild-type and ErbB4-KO mice were used to generate glia-free dissociated hippocampal neurons for use in immunofluorescence experiments. All procedures were approved by the National Institutes of Health Office of Laboratory Animal Welfare.

Antibodies. Mouse monoclonal antibody mAb-77 raised against the extracellular domain of ErbB4 (Chen et al., 1996) was from Thermo Scientific. Rabbit polyclonal sc-283 against the C terminus of ErbB4 was from Santa Cruz Biotechnologies (lots E1805 and L0904). Rabbit polyclonal anti-neurogranin, mouse monoclonal anti-GAD67, and rabbit anti-vesicular GABA transporter (VGAT) were from Chemicon, mouse monoclonal anti-parvalbumin was from Sigma-Aldrich, and mouse monoclonal anti-cholecystokinin (CCK) was from the CURE/Digestive Diseases Research Center (University of California, Los Angeles, CA). A goat polyclonal antibody against glutathione-S-transferase (GST) was from GE Healthcare. A human ErbB4 cDNA under the control of the CMV (cytomegalovirus) promoter has been described previously (Garcia et al., 2000).

Generation of hybridoma cell lines. The nucleotide sequence corresponding to amino acids 1036 through 1239 of mouse ErbB4 [closely resembling the aggregate immunogen sequence used by Zhu et al. (1995) to raise three separate polyclonal antisera against ErbB4] was amplified by PCR from mouse brain cDNA and subcloned into pGEX-2T (GE Healthcare). The resultant glutathione-S-transferase fusion protein
(GSTmB4) was used to immunize four rabbits (5938-5941; Covance). Rabbit 5941 was killed, and the spleen removed and used to derive B-lymphocyte $\times$ plasmacytoma hybridoma cell lines (Epitomics) (Spieker-Polet et al., 1995). After ELISA screenings and Western blotting, three hybridoma cell lines (mAb-6, mAb-7, mAb-10) were selected for additional analyses.

Western blotting. Mouse hippocampal lysate proteins were sizefractionated by SDS-PAGE using $4-12 \%$ acrylamide gradient gels (Invitrogen) and electrophoretically transferred onto nitrocellulose membranes. Excess binding capacities were blocked with 5\% nonfat dry milk in Tris-buffered saline ( $137 \mathrm{~mm} \mathrm{NaCl}, 3 \mathrm{~mm} \mathrm{KCl}, 25 \mathrm{~mm}$ Tris-HCl, $\mathrm{pH} 7.4$ ) containing $0.1 \%$ Tween 20 (TBS-T). Membranes were incubated overnight with $0.2 \mu \mathrm{g} / \mathrm{ml}$ primary antibody in $3 \%$ bovine serum albumin (BSA) in TBS-T. Antibody binding was visualized with enhanced chemiluminescence (ECL) (GE Healthcare) using a secondary donkey antirabbit antibody conjugated to horseradish peroxidase (GE Healthcare).

Immunoprecipitation. To test antibody performance in immunoprecipitation, a tissue lysate was prepared from mouse neocortex by homogenization in $20 \mathrm{vol}$ of $10 \mathrm{~mm}$ Tris-Cl, pH 7.5, $150 \mathrm{~mm} \mathrm{NaCl}, 1 \%$ $\mathrm{NP}-40$ in the presence of protease inhibitors (Complete protease inhibitor mixture; Roche) using a glass homogenizer. The homogenate was cleared by centrifugation at $5000 \times g$ for $10 \mathrm{~min}$, and the resultant supernatant was diluted to $1 \mathrm{mg} / \mathrm{ml}$ with IP buffer ( $10 \mathrm{~mm}$ Tris-Cl, $\mathrm{pH}$ $7.5,150 \mathrm{~mm} \mathrm{NaCl}, 0.2 \% \mathrm{NP}-40$, protease inhibitors). For each of the three monoclonal ErbB4 antibodies, $5 \mathrm{ml}$ of conditioned hybridoma supernatant were incubated with $100 \mu \mathrm{l}$ of washed protein A-Sepharose (Santa Cruz) for $2 \mathrm{~h}$ at $4^{\circ} \mathrm{C}$. The immobilized antibodies were washed three times with IP buffer and then incubated for $3 \mathrm{~h}$ at $4^{\circ} \mathrm{C}$ with the diluted lysate ( $1 \mathrm{mg}$ of total protein). After three washes with IP buffer, proteins were eluted in SDS sample buffer and subjected to Western blotting. As a negative control for immunoprecipitation, a separate reaction using $2 \mu \mathrm{g}$ of normal rabbit IgG (Santa Cruz) instead of hybridoma supernatant was included.

Cell culture and transfections. Dissociated hippocampal neurons from E19 rat or E18 mouse fetuses were plated on poly-D-lysine- and laminincoated coverslips at a density of $8 \times 10^{4}$ cells $/ \mathrm{ml}$ and cultured for $8 \mathrm{~d}$ in vitro (DIV) in Neurobasal medium supplemented with B27 (Invitrogen) as described previously (Brewer et al., 1993; Longart et al., 2004). For analysis of axonal ErbB4 expression, rat neurons were transfected at DIV 7 with a vector expressing SNPH $\Delta$ MT-GFP (Kang et al., 2008) using Lipofectamine 2000 (Invitrogen) and incubated for $24 \mathrm{~h}$.

Immunocytochemistry and immunohistochemistry. For double immunofluorescence of ErbB4 and GAD67 in cultured hippocampal neurons, cells were fixed at DIV 8 with $4 \%$ paraformaldehyde (PFA), permeabilized with $0.1 \%$ Triton $\mathrm{X}-100$, and incubated with either undiluted conditioned hybridoma supernatants or sc-283 $(0.2 \mu \mathrm{g} /$ $\mathrm{ml}$ ), and with mouse monoclonal anti-GAD67 (1:5000). For ErbB4/ VGAT double immunofluorescence, mouse monoclonal antibody Ab-77 against ErbB4 $(1 \mu \mathrm{g} / \mathrm{ml})$ and rabbit polyclonal antibody against VGAT $(0.5 \mu \mathrm{g} / \mathrm{ml})$ were used to label hippocampal neurons at DIV 14. Primary antibody binding was visualized with secondary antibodies conjugated to Cy3 or Alexa Fluor 594 (ErbB4) and Alexa Fluor 488 (GAD67, VGAT), and analyzed in a Zeiss Axiovert $135 \mathrm{TV}$ fluorescence microscope at $63 \times$ magnification.

For immunohistochemistry of hippocampal sections, adult anesthetized wild-type C57BL/6J and ErbB4-KO mice (10-14 weeks) were fixed by cardiac perfusion with 4\% PFA in PBS, pH 7.4, over 15 min. Dissected brains were postfixed overnight at $4^{\circ} \mathrm{C}$ and cut horizontally on a vibratome $(50 \mu \mathrm{m})$. Sections containing the hippocampus were processed for double immunofluorescence in $0.1 \mathrm{M}$ PBS, $\mathrm{pH}$ 7.4, as follows: two washes in $0.1 \mathrm{M}$ PBS, 10 min each; 90 min blocking in $0.1 \mathrm{M}$ PBS containing $10 \%$ normal goat serum, $1 \% \mathrm{BSA}$, and $0.25 \%$ Triton X-100; primary antibody incubation for $40 \mathrm{~h}$ at $4^{\circ} \mathrm{C}$ in blocking solution; three washes; secondary antibody for $90 \mathrm{~min}$ at room temperature in blocking solution; three washes; and mounting in Mowiol-DABCO. Primary antibody concentrations were as follows: $\mathrm{mAb}-6, \mathrm{mAb}-7, \mathrm{mAb}-10,3 \mu \mathrm{g} / \mathrm{ml} ; \mathrm{mAb}-$ 77, $3 \mu \mathrm{g} / \mathrm{ml}$; sc-283, $50 \mathrm{ng} / \mathrm{ml}$; GAD67, 1:5000; neurogranin, 1:2000; parvalbumin, 1:3000; CCK, 1:500. Control sections without primary and/or secondary antibodies exhibited complete absence of neuronal 
staining. Sections were analyzed using a confocal microscope (Zeiss 510 Meta) at 20, 40, or $63 \times$ magnification. Images are representative for the staining pattern and were adjusted for overall brightness and contrast using Adobe Photoshop CS.

For immunoelectron microscopy, 5-week-old male Sprague Dawley rats were perfused through the heart with $4 \%$ paraformaldehyde in a phosphate buffer. Parasagittal sections were cut at $50 \mu \mathrm{m}$ and stored frozen in 30\% sucrose in PBS. After incubation in 10\% normal goat serum (NGS), sections were incubated overnight with anti-ErbB4 antibody mAb-10. Antibody binding was visualized with a horseradish peroxidase-conjugated secondary antibody using diaminobenzidine (DAB) as substrate (Vectastain ABC kit; Vector Laboratories). After labeling, sections were postfixed in $2 \%$ glutaraldehyde in cacodylate buffer, and then in osmium tetroxide, dehydrated in an alcohol series, and embedded in Epon 812 for additional thin sectioning for EM. Similar results were obtained in experiments in which the primary antibody was used at either 4 or $3 \mu \mathrm{g} / \mathrm{ml}$ plus a brief preincubation in $0.3 \% \mathrm{H}_{2} \mathrm{O}_{2}$ before the NGS block. Additionally, experiments were performed with the polyclonal anti-ErbB4 antibody HL5941 using DAB with and without silver/ gold toning and sections from a second rat. Results were similar to those with the monoclonal antibody mAb-10. Control sections minus the primary antibody were included in all experiments and essentially were void of any discernible labeling. To assess ErbB4-IR in spine synapses, numerous pictures of CA1 strata pyramidale and radiatum were taken and inspected for granular reaction products in postsynaptic spine profile as identified by their shape, asymmetric density, and straight cleft. Potential labeling was compared based on the contrast of surrounding structures for any particular micrograph. Spine labeling was considered definitive if there were grains at both the postsynaptic density (PSD) and in parts of the cytoplasm, as unlabeled PSDs by themselves tend to be darker than their surrounding processes.

Whole-cell recordings and single-cell reverse transcription-PCR. Recordings were done on acute slices prepared from 2- to 3-week-old C57BL/6 mice. Electrophysiological characterization of CA1 interneurons and pyramidal cells was performed by whole-cell patch-clamp recording using a potassium gluconate-based intracellular solution containing biocytin for post hoc morphological processing of recorded cells, as described previously (Lawrence et al., 2006). At the end of the recording, the cytoplasm of the cell was aspirated into the recording pipette while maintaining the tight seal. Then, the pipette was carefully removed to allow outside-out patch formation, and its contents were expelled into a test tube. Reverse transcription (RT) was performed in a final volume of $10 \mu \mathrm{l}$ as described previously (Lambolez et al., 1992). Next, two consecutive rounds of PCR using outer and nested primer sets were performed essentially as described previously (Cauli et al., 1997). For the first PCR, all targets were amplified simultaneously using outer primer pairs for GAD65, GAD67, VGluT1, ErbB4, ErbB3, and EGF receptor (EGFR) (for primer sequences, see supplemental Table S1, available at www.jneurosci.org as supplemental material), $2.5 \mathrm{U}$ of Taq polymerase (QIAGEN), and 20 pmol of each primer in a final volume of $100 \mu$ l. Targets were amplified for 21 cycles, each comprising a $94^{\circ} \mathrm{C}$ denaturation step for $30 \mathrm{~s}, 60^{\circ} \mathrm{C}$ annealing for $30 \mathrm{~s}$, and $72^{\circ} \mathrm{C}$ extension for $30 \mathrm{~s}$. Individual targets were separately reamplified using 35 cycles of PCR as described above with 2 $\mu \mathrm{l}$ of the first PCR product as template and specific nested primer sets (supplemental Table S1, available at www.jneurosci.org as supplemental material). Products were assayed on $2 \%$ agarose gels stained with ethidium bromide, using HaeIII-digested $\Phi X 174-D N A$ as a molecular weight marker. All primer sets were designed to span exon boundaries and were verified on $1 \mathrm{ng}$ of total RNA purified from mouse whole brain using the RT-PCR protocol described above. Primer sequences for ErbB receptors were additionally designed to bind to regions not reported to undergo alternative splicing. A control for mRNA contamination from surrounding tissue was performed by placing a patch pipette in the slice without establishing a seal. Positive pressure was then interrupted, and after the removal of the pipette, its content was processed as described. No PCR product was obtained using this protocol $(n=5)$.
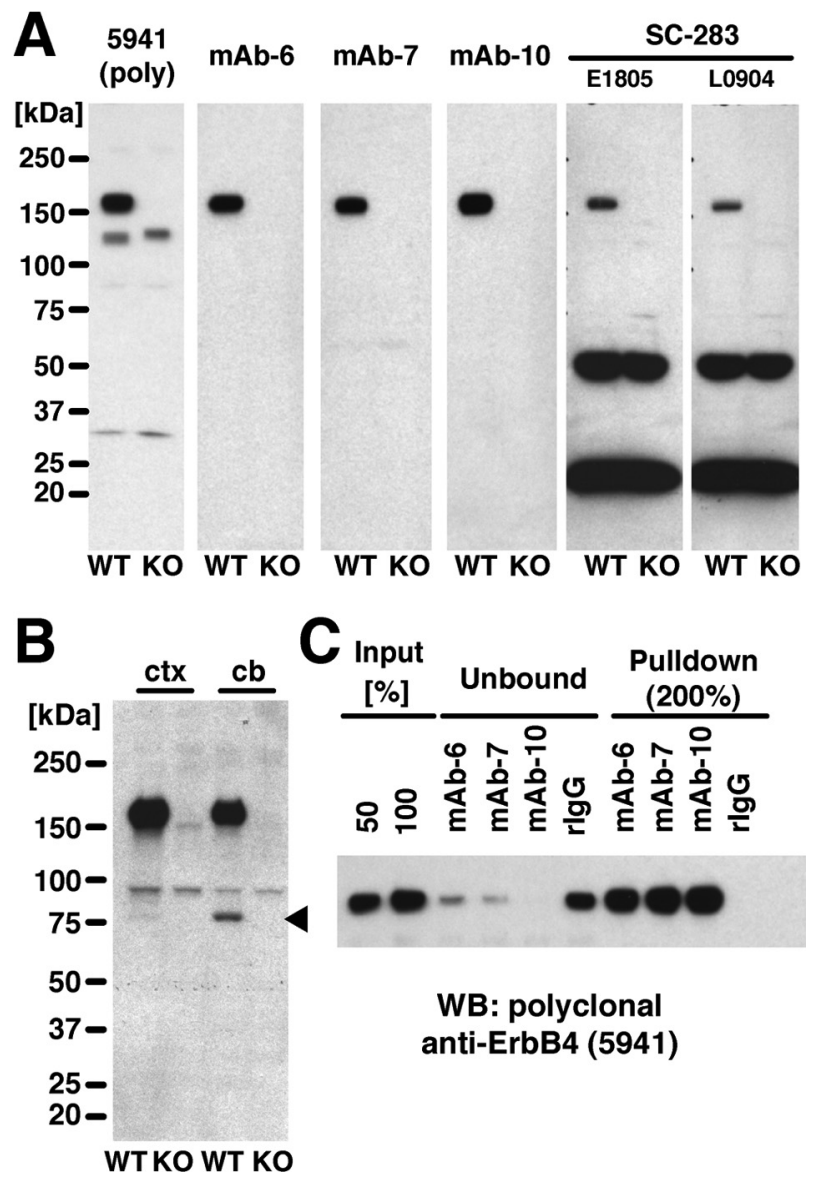

Figure 1. Generation and characterization of rabbit monoclonal anti-ErbB4 antibodies. A, Rabbit monoclonal antibodies against ErbB4 detect a single protein of $\sim 180 \mathrm{kDa}$ apparent molecular mass in immunoblots of adult mouse hippocampal extracts. Blots containing extracts (50 $\mu \mathrm{g} /$ lane) from wild-type (WT) and ErbB4-KO (KO) mice were probed with the polyclonal anti-ErbB4 antiserum 5941, monoclonal antibodies mAb-6, mAb-7, mAb-10, and sc-283 (two different lots shown). All antibodies were used at $0.2 \mu \mathrm{g} / \mathrm{ml}$. Molecular masses of reference proteins are as indicated. $\boldsymbol{B}$, Proteolytic processing of ErbB4 is low in the hippocampus. Crude membrane fractions (60 $\mu \mathrm{g} /$ lane) of mouse cortex (ctx) and cerebellum (cb) from wild-type and ErbB4-K0 mice were probed by immunoblotting with mAb-10 (1 $\mu \mathrm{g} / \mathrm{ml})$. The arrowhead marks the position of the $80 \mathrm{kDa}$ ErbB4-ICD fragment visible in cerebellar and, to a much smaller extent, in cortical extracts. Note that, to detect the ErbB4-ICD, a more highly enriched protein fraction was loaded, mAb-10 was used at higher concentrations, and exposure times were longer than in A. C, Monoclonal antibodies effectively bind the native receptor in immunoprecipitation of ErbB4 from lysates of mouse neocortex. Lysate input, as well as flow-through (unbound) and immunoprecipitate (pulldown) fractions obtained with ErbB4 monoclonal antibodies and the normal rabbit lgG negative control ( $r l g G)$, are shown. Sample volumes were 50 and $100 \%$ for the input, $100 \%$ for flow-through fractions, and $200 \%$ for immunoprecipitates. The Western blot was probed with polyclonal ErbB4 antibody 5941 as described in $\boldsymbol{A}$.

\section{Results}

\section{Generation and validation of rabbit monoclonal}

\section{ErbB4 antibodies}

A 204 aa segment within the intracellular domain (ICD) of mouse ErbB4 downstream of the tyrosine kinase domain was expressed as a GST fusion protein to generate monoclonal antibodies (supplemental Fig. S1, available at www.jneurosci.org as supplemental material). The sequence closely resembles a region previously used to raise antibodies that identified ErbB4 receptor protein at the neuromuscular junction and in migrating interneurons in the developing CNS (Zhu et al., 1995; Yau et al., 2003). It also avoids the $\mathrm{C}$ terminus that binds PDZ (postsynaptic density-95/Discs large/zona occludens-1) domain-containing proteins of the 

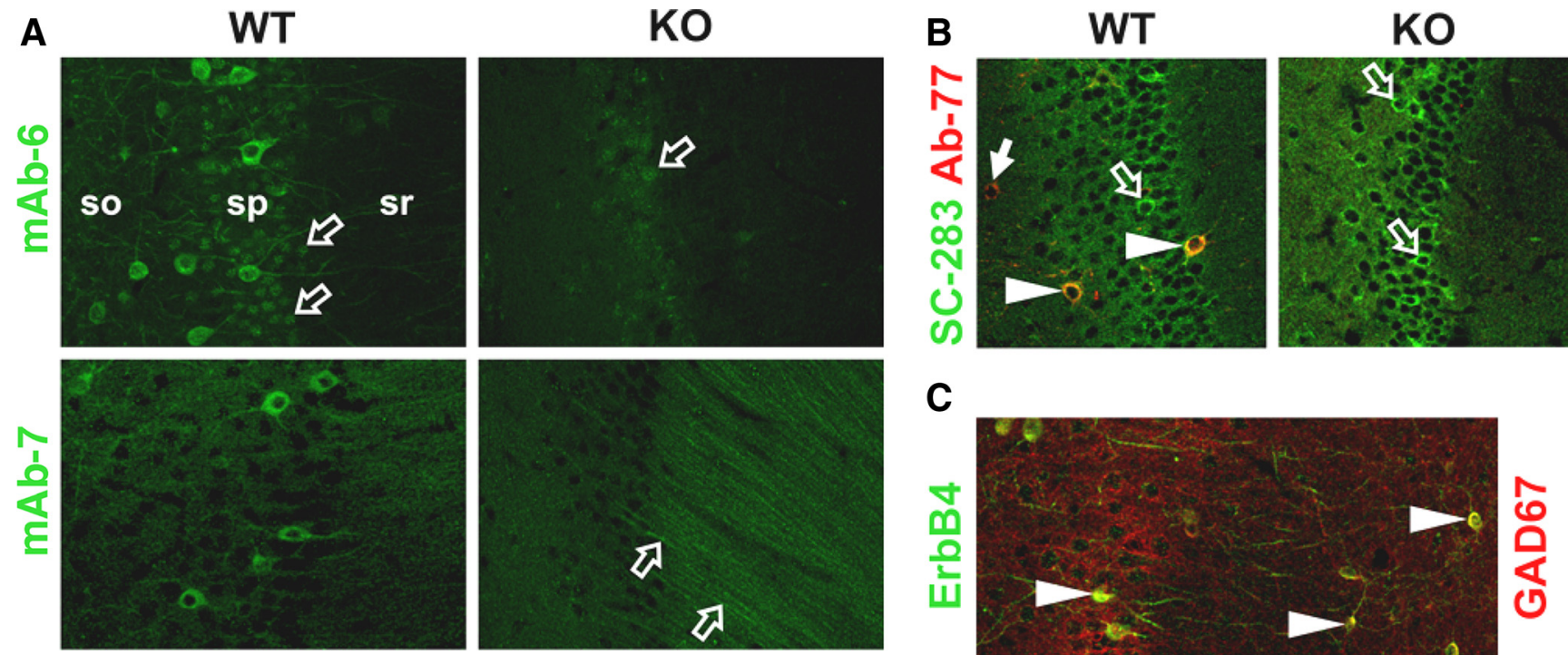

C
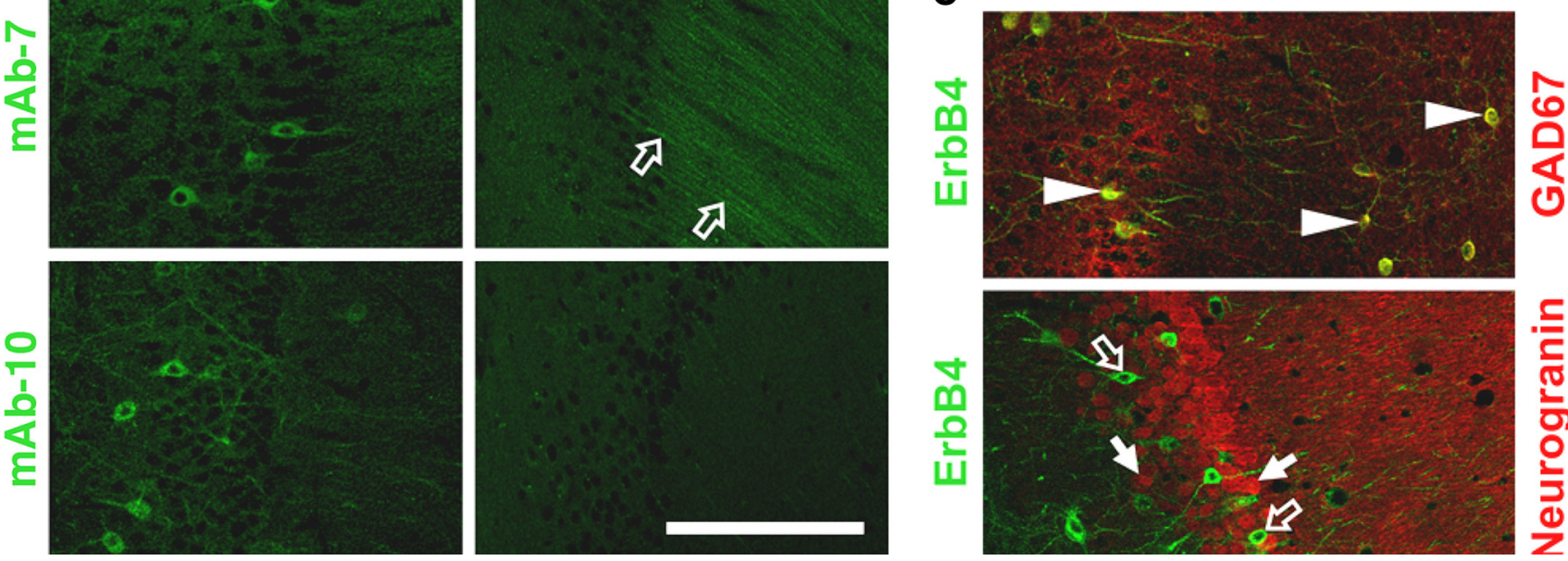

Figure 2. GAD67-immunoreactive interneurons, but not pyramidal cells, express ErbB4 in CA1 of the mouse hippocampus. $A$, Immunofluorescence of ErbB4 in sections from wild-type (WT) and ErbB4-KO (KO) mice using mAb-6, mAb-7, and mAb-10. All three antibodies selectively label dispersed cell bodies and dendrites in the stratum pyramidale and, to a lesser extent, in strata oriens and radiatum. The open arrows indicate minor nonspecific labeling of cell nuclei by mAb-6, and apical dendrites by mAb-7, in both WT and K0 sections. Layers are indicated (so, stratum oriens; $\mathrm{sp}$, stratum pyramidale; sr, stratum radiatum). B, sc-283 labels numerous cells in the pyramidal cell layer of ErbB4-K0 mice. Overlay images show ErbB4 immunofluorescence using sc-283 (green) and mAb-77 (red) in wild-type and ErbB4-K0 sections. Layers shown are the stratum pyramidale and parts of the adjacent strata oriens and radiatum. C, ErbB4-IR colocalizes with GAD67, but not with the pyramidal neuron-selective marker neurogranin. Overlay images of ErbB4/GAD67 double immunofluorescence (top) using mAb-10 (green) and mouse monoclonal anti-GAD67 (red), and of ErbB4/Neurogranin (bottom) using mAb-77 (green) and rabbit polyclonal anti-neurogranin (red). The arrowheads in $\boldsymbol{B}$ and $\boldsymbol{C}$ indicate cells showing overlay of signals from both channels, whereas the filled and open arrows indicate cells with signals only from either the red or green channel, respectively. Scale bar, $100 \mu \mathrm{m}$.

postsynaptic density (Garcia et al., 2000; Huang et al., 2000). We chose rabbit as the host species because it typically gives rise to antibodies of higher affinity compared with the mouse. Based on high ErbB4-reactive antibody titers and the lack of major crossreacting protein bands (Fig. $1 A$, left), rabbit 5941 was subjected to splenectomy and fusion of B-lymphocytes to plasmacytoma cells. Three hybridoma lines, mAb-6, mAb-7, and mAb-10, produced antibodies exclusively reacting with the $180 \mathrm{kDa}$ apparent molecular mass ErbB4 protein in Western blots of wild-type mouse hippocampal extracts, as evidenced by the absence of this band in corresponding extracts from ErbB4-KO mice (Fig. $1 \mathrm{~A}$, middle). No other immunoreactive bands were observed. In contrast, two different lots of sc-283, a polyclonal ErbB4 antibody that has been used previously to analyze ErbB4 expression in the CNS (Mechawar et al., 2007; Thompson et al., 2007), only weakly reacted with ErbB4 and exhibited major cross-reactions with proteins of $\sim 50$ and $25 \mathrm{kDa}$ apparent molecular mass that were present in both wild-type and ErbB4-KO extracts (Fig. $1 A$, right). This observation was additionally confirmed using two other lots of the same antibody available at the time of this study, and a corresponding antibody preparation from goat (sc-283G) (data not shown). The observed pattern of sc-283 immunoreactivity was virtually identical with published Western blot results obtained with this antibody using mouse frontal cortex and hippocampus, and monkey prefrontal cortex (Mechawar et al., 2007; Thompson et al., 2007).
ErbB4 isoforms containing the alternatively spliced JM-a exon can undergo ectodomain shedding by the matrix metalloprotease TACE (tumor necrosis factor- $\alpha$-converting enzyme), resulting in the generation of a $\sim 80 \mathrm{kDa}$ membrane-bound protein fragment containing the ICD (Elenius et al., 1997; Rio et al., 2000). Additional intracellular processing of this fragment by $\gamma$-secretase has been shown in non-neuronal cell lines to generate a slightly smaller soluble ICD fragment that translocates to the nucleus (Rio et al., 2000; Zhou and Carpenter, 2000; Ni et al., 2001). The presence of multiple immunoreactive bands and labeling of pyramidal neuron nuclei with sc-283 has been suggested to reflect ErbB4 processing in monkey cortical tissue (Thompson et al., 2007). However, as apparent from the immunoblotting results shown in Figure $1 A$, no such additional bands were observed with any of our monoclonal antibodies. By RT-PCR, JM-a isoform expression is low in mouse cerebral cortex but is high in cerebellum (Elenius et al., 1997). To verify that our antibodies are capable of detecting the ErbB4-ICD fragment, we compared crude membrane preparations from mouse cortex and cerebellum. As shown in Figure $1 \mathrm{~B}, \mathrm{mAb}-10$ labeled full-length ErbB4 in both cortical and cerebellar extracts. In addition, a second protein of $\sim 80 \mathrm{kDa}$ apparent molecular mass was detected in wild-type but not ErbB4-KO cerebellum, consistent with it representing the processed ErbB4-ICD. The intensity of the corresponding band was much weaker in cortical extracts despite the 
A

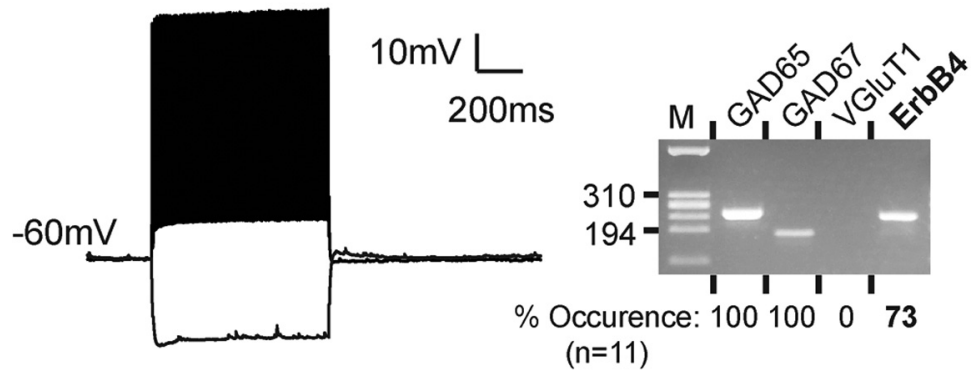

B

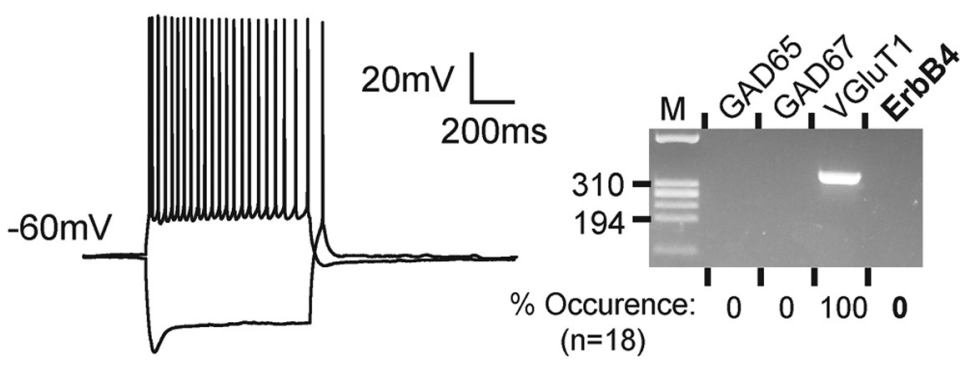

Figure 3. ErbB4 mRNA is undetectable by single-cell PCR in electrophysiologically and molecularly identified CA1 pyramidal neurons. Representative examples of action potential discharges from a fast-spiking inhibitory $(\boldsymbol{A})$ and a pyramidal neuron $(\boldsymbol{B})$ in response to 500 and $200 \mathrm{pA}$ depolarizing current injections, respectively, are shown on the left. Membrane potentials were adjusted as indicated. Results of the corresponding scPCRanalyses of these neurons are shown on the right. Haelll-digested $\Phi X 174$ DNA was used as size reference (" $\mathrm{M}$," 310 and 194 bp fragments indicated). Results from the respective population analyses are shown below each gel image. ErbB4 was not detected in any of the 18 pyramidal cells analyzed (positive for the glutamatergic marker VGluT1), whereas 8 of 11 GAD65/GAD67-positive interneurons were positive.

greater abundance of full-length ErbB4 and could only be revealed on prolonged film exposure. Based on these findings, we conclude that the extent of ErbB4 processing is likely to be low in the adult cortex.

Having shown that our monoclonal antibodies detect denatured ErbB4 in immunoblotting, we next tested whether they also effectively bind the native receptor by immunoprecipitating ErbB4 from NP-40-solubilized mouse brain lysates. As shown in Figure $1 C$, all three antibodies almost quantitatively removed ErbB4 from the lysate, suggesting that their epitopes are accessible within the folded receptor. Additional biochemical analyses using a series of incrementally truncated GST fusion proteins revealed that $\mathrm{mAb}-6, \mathrm{mAb}-7$, and $\mathrm{mAb}-10$ react with distinct, non-overlapping sequences within the immunogenic ErbB4 fragment (supplemental Fig. S2 A, available at www.jneurosci.org as supplemental material). Last, we tested our antibodies for species selectivity by immunoblotting (supplemental Fig. S2 B, available at www.jneurosci.org as supplemental material) and found that mAb-7 and mAb-10 reacted equally well with ErbB4 of mouse, rat, and human origin, whereas $m A b-6$ reacted with mouse and human, but not with rat ErbB4.

\section{ErbB4 immunoreactivity in mouse CA1 is restricted to GAD67-positive interneurons}

Next, we compared the ErbB4 labeling pattern of PFA-fixed hippocampal sections from wild-type and ErbB4-KO mice. As shown in Figure $2 \mathrm{~A}$, all three rabbit monoclonal antibodies labeled the somata and neurites of numerous cells dispersed across all layers in CA1, with the highest densities in the strata oriens and pyramidale. This pattern, indicative of GABAergic interneurons, was entirely absent from the corresponding ErbB4-KO controls.
Inspection of residual fluorescence signals in ErbB4-KO sections revealed minor nonspecific binding of $\mathrm{mAb}-6$ to cell nuclei in stratum pyramidale and of $\mathrm{mAb}-7$ to apical dendrites in stratum radiatum. In contrast, $\mathrm{mAb}-10$ showed no discernible nonspecific binding in ErbB4-KO sections and thus presented the most selective labeling pattern toward ErbB4 in PFA-fixed brain tissue.

sc-283 has been used in numerous studies to analyze the cellular expression pattern of ErbB4 in the rodent and primate brain (Gerecke et al., 2001; Mechawar et al., 2007; Thompson et al., 2007). However, as shown in Figure 1, several antibody lots that were available at the time of this study strongly cross-react with other proteins, indicating possible problems with the interpretation of immunohistological data derived with this antibody preparation. Indeed, and as illustrated in Figure $2 B$, labeling of ErbB4-KO hippocampal sections with sc283 revealed some strongly and numerous weakly immunoreactive cells in stratum pyramidale. Double immunofluorescence of wild-type sections with sc-283 and an antibody against the extracellular domain of ErbB4 [mAb-77 (Chen et al., 1996); a mouse monoclonal antibody that in our hands selectively detects ErbB4 in PFAfixed sections] revealed numerous cells immunoreactive with sc- 283 but not with mAb-77, and vice versa. sc- 283 also labeled many neurons in hippocampal cultures from ErbB4-KO mice (supplemental Fig. S3, available at www.jneurosci.org as supplemental material).

To analyze neuron type-specific ErbB4 immunoreactivity, we first double-labeled hippocampal sections for ErbB4 and GAD67 using $\mathrm{mAb}-10$ and a mouse monoclonal antibody for GAD67. As shown in a representative image in Figure 2C, all ErbB4immunoreactive cells were also positive for GAD67. Conversely, many, but not all, GAD67-immunoreactive neurons were ErbB4positive. The same relationship between ErbB4 and GAD67 immunoreactivity was observed in cultured DIV 8 hippocampal neurons (supplemental Fig. S3, available at www.jneurosci.org as supplemental material). In contrast, double immunofluorescence of ErbB4 and neurogranin, a marker for pyramidal cells in the neocortex and hippocampus (Singec et al., 2004), resulted in a pattern that was mutually exclusive with ErbB4 (Fig. 2C). Together, we conclude that our antibodies faithfully identify ErbB4expressing interneurons and that immunoreactivity observed in other cell types, particularly in pyramidal cells, must be cautiously interpreted.

\section{ErbB4 mRNA in functionally identified interneurons and pyramidal neurons}

To ascertain the absence of ErbB4 expression in pyramidal neurons, we next tested individual glutamatergic and GABAergic neurons from 2- to 3-week-old mice by a combination of patchclamp electrophysiology and single-cell RT-PCR (scPCR). In this approach, neurons were first electrophysiologically characterized and their cell contents were then assayed for expression of 
mRNAs encoding ErbB4 and the neurontype selective markers GAD65, GAD67, and VGluT1. CA1 putative interneurons were identified by their nonpyramidal morphology, and by their ability to generate high-frequency spike discharges $(>40$ $\mathrm{Hz}$ ), with little accommodation and short action potentials (McBain and Fisahn, 2001) (Fig. 3A). Interneuron identity was further confirmed by amplification of PCR fragments for GAD65 and GAD67, and the absence of the corresponding PCR fragment for the vesicular glutamate transporter VGluT1. Conversely, CA1 pyramidal neurons displayed accommodating low-frequency spike discharges and tested positive for VGluT1 but not GAD65 or GAD67 in scPCR (Fig. 3B). Consistent with our results obtained by immunohistochemistry, ErbB4 mRNA was detected in a majority of verified interneurons ( $n=8$ of $11 ; 73 \%)$, but not in pyramidal cells ( $n=0$ of 18 ) (for individual results, see supplemental Table S2, available at www.jneurosci.org as supplemental material). We also included ErbB3 and EGFR in these assays but were unable to detect their mRNAs in any of the tested neurons. Since the corresponding primer sets reproducibly amplified their targets from nanogram quantities of whole-brain RNA (supplemental Fig. S4, available at www.jneurosci.org as supplemental material), we conclude that ErbB3 and EGFR mRNA levels are very low in both neuron types at the tested age. This finding is consistent with the restricted expression of ErbB3 in glial cells (Gerecke et al., 2001) and the dramatic downregulation of hippocampal EGFR expression after birth (Fox and Kornblum, 2005).

\section{Subcellular distribution of ErbB4 within inhibitory interneurons}

Knowledge of the subcellular localization of ErbB4 is important to understand which cellular functions are regulated by the activated receptor. To address this, we used immunoelectron microscopy to examine ErbB4 expression at the ultrastructural level. Fifty micrometer rat hippocampal sections were labeled with $\mathrm{mAb}-10$ using a peroxidase-conjugated secondary antibody and $\mathrm{DAB}$, and processed for electron microscopy. Figure 4 shows representative images taken from area CA1 at the boundary between strata pyramidale and radiatum. Interneurons, characterized by their aspiny dendrites, were intensely labeled. In contrast, pyramidal cell bodies were consistently, and postsynaptic spines overwhelmingly, immunonegative for ErbB4 (Fig. $4 A, E)$. Quantitative assessment of a semirandom sample of 218 spine synapse profiles (identified by shape, asymmetric density, and straight cleft) revealed only two spines with moderate labeling. However, these likely represent background staining as there was no evidence of cytoplasmic labeling in either (see also Materials and Methods). Within the same sample, we identified seven interneuron profiles with shaft synapses, all of which were labeled. Within interneuron dendrites,
ErbB4-IR was found both at the cell surface as well as in internal membranous structures, including vesicles and tubulovesicular structures (Fig. $4 B-E$ ). This observation is consistent with our previous finding of a substantial fraction of ErbB4 protein that is located in intracellular compartments of cultured hippocampal interneurons (Longart et al., 2007). As expected from the known association of ErbB4 with the postsynaptic density, ErbB4-IR at the plasma membrane was strong in areas juxtaposed to presumptive glutamatergic presynaptic terminals (Fig. $4 B-D$, arrows); excitatory synapses were identified by the presence of an asymmetric density, a wide cleft, and relatively rounded vesicles. Interestingly, dense clusters of ErbB4-IR were also frequently observed adjacent to postsynaptic sites (Fig. $4 B, C$, arrowheads), suggesting that ErbB4 might also accumulate perisynaptically, a finding that is potentially significant given the involvement of NRG/ErbB signaling in glutamate receptor trafficking (Gu et al., 2005; Kwon et al., 2005).

Together, these data provide strong support for ErbB4 immunoreactivity in dendrites and somata of GAD67-positive cells in CA1 and in dissociated hippocampal neurons (Fig. 2; supplemental Fig. S3, available at www.jneurosci.org as supplemental material), consistent with its postsynaptic localization at glutamatergic terminals (Garcia et al., 2000; Huang et al., 2000). However, recent work in the mouse prefrontal cortex has implicated presynaptic ErbB4 in the regulation of transmitter release from GABAergic interneurons (Woo et al., 2007). To investigate in 

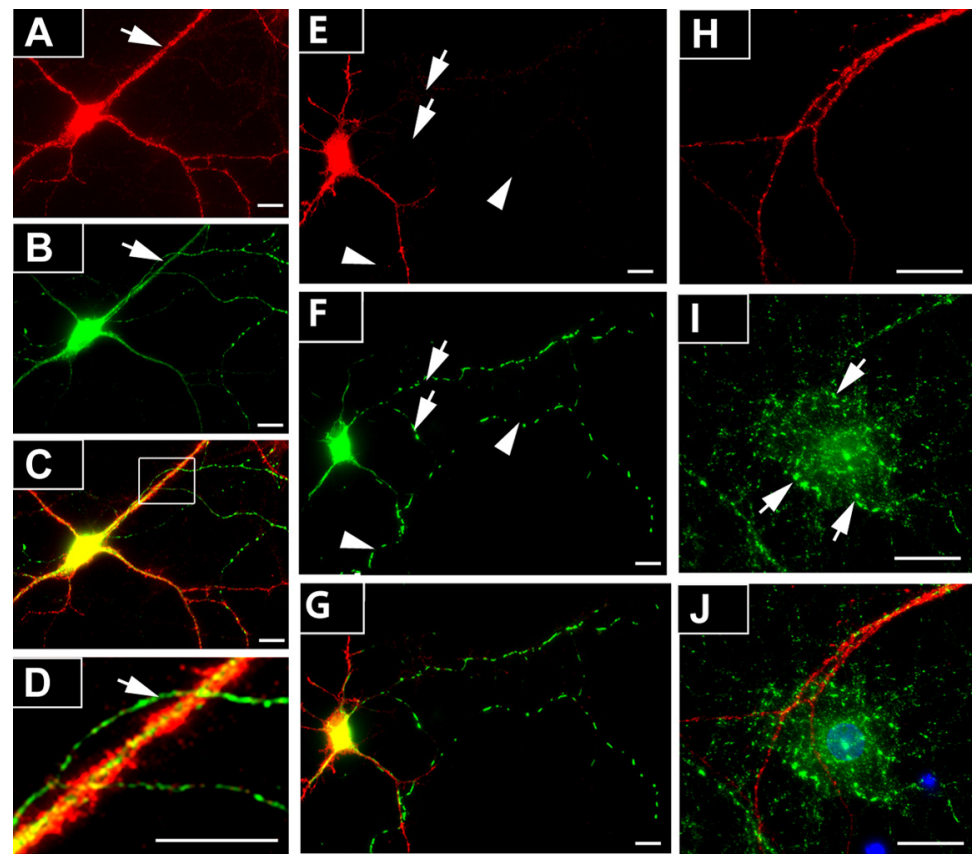

Figure 5. ErbB4 immunoreactivity is mostly absent from axons and is undetectable in axon terminals of dissociated hippocampal neurons. $\boldsymbol{A}-\boldsymbol{D}$, DIV 8 neurons were double-labeled for $\operatorname{ErbB4}(\boldsymbol{A})$ and GAD67 (B) using mAb-10 and mouse mAb against GAD67. As shown in the overlay image $(\boldsymbol{C})$ and the magnified area in $\boldsymbol{D}$, the GAD67-immunoreactive axon (arrow) is immunonegative for ErbB4, in contrast to the cell body and dendrites. $\boldsymbol{E}-\boldsymbol{G}$, Representative image of ErbB4 immunofluorescence ( $\boldsymbol{E}$; red) in DIV 8 neurons expressing SNPH $\triangle$ MT-GFP ( $F$; green). Colocalization of ErbB4 and SNPH $\triangle M$ MT-GFP is apparent in soma and dendrites, but not in the axon (arrows). Note that the distribution of SNPH $\Delta$ MT-GFP in axons appears dotted because of its association with mobile mitochondria. The arrowheads indicate an axonal process that originates from a different cell. $\boldsymbol{H}-\boldsymbol{J}$, Lack of colocalization of ErbB4 ( $\boldsymbol{H}$; red) and VGAT ( $\boldsymbol{I}$; green) immunoreactivity in GABAergic terminals (arrows). Note the ErbB4-immunoreactive dendrite that runs across the ErbB4-negative (presumably pyramidal) neuron. The overlay image $(J)$ additionally includes a DAPI $\left(4^{\prime}, 6^{\prime}\right.$ diamidino-2-phenylindole) staining of cell nuclei (blue). Scale bars, $50 \mu \mathrm{m}$.
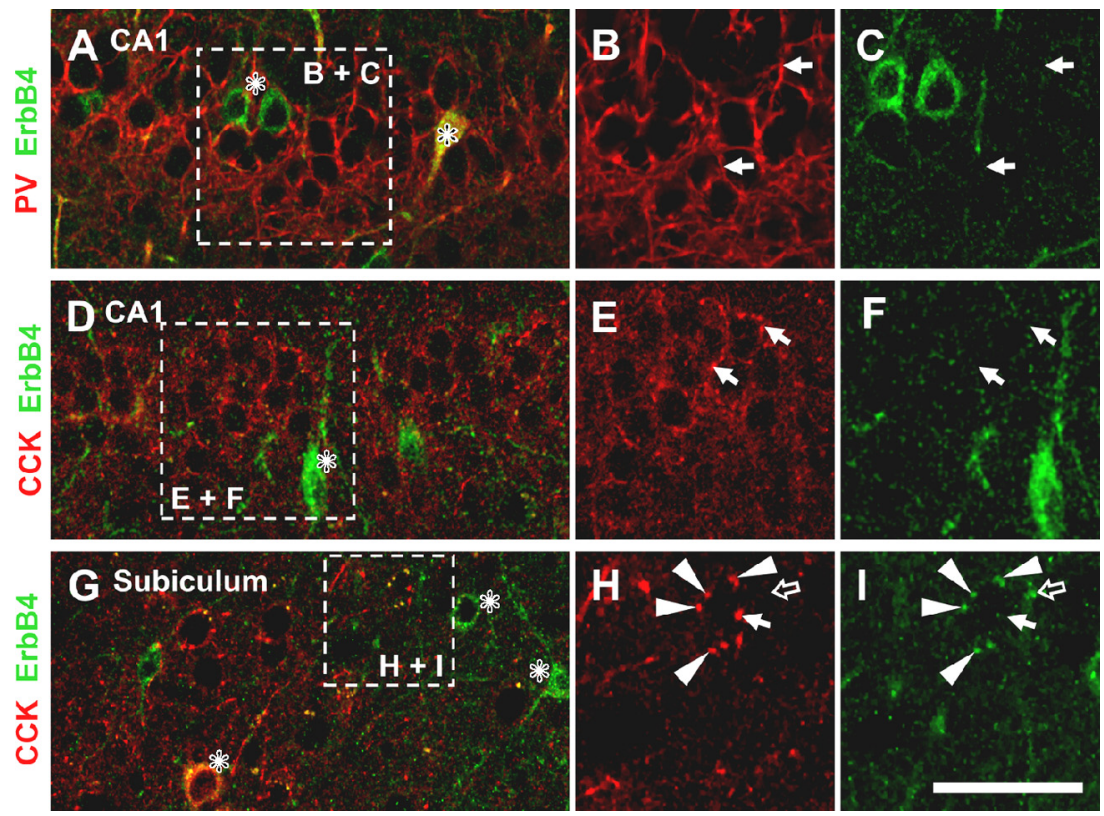

Figure 6. ErbB4 immunoreactivity is absent from basket cell terminals in CA1. Hippocampal sections were double-labeled for ErbB4 (mAb-10; green) and PV ( $\boldsymbol{A}-\boldsymbol{C})$ or CCK (D-I) (red). The boxed areas in overlay images on the left outline areas magnified in single-channel images on the right. For CCK interneurons, an area of the subiculum containing ErbB4-immunoreactive baskets $(\mathbf{G}-\boldsymbol{I})$ is shown in addition to the $\mathbf{C A 1}(\boldsymbol{D}-\boldsymbol{F})$. The asterisks $\left(^{*}\right)$ denote cell somata of ErbB4-immunoreactive interneuron somata, some of which are double-labeled with the respective interneuron marker; the solid arrows $(\rightarrow)$ indicate examples of baskets that are immunonegative for ErbB4; the arrowheads $(\rightarrow)$ point to CCK interneuron baskets that coexpress ErbB4; the open arrow $\Leftrightarrow)$ indicates a punctate ErbB4 signal in the subiculum that is distinct from the nearby ErbB4-immunoreactive CCK basket. Scale bars: $A, D, G, 50 \mu \mathrm{m} ; B, C, E, F, 38 \mu \mathrm{m} ; \boldsymbol{H}, I, 25 \mu \mathrm{m}$. more detail whether axonal ErbB4 expression is observed in hippocampal neurons, we first labeled cultured dissociated neurons at DIV 8 for ErbB4 and GAD67. GAD67 immunoreactivity is present in axon processes and accumulates at terminals, as well as in cell somata and proximal dendrites in which it is diffusely distributed (Kaufman et al., 1991). Because of the tight correlation between GABAergic phenotype and ErbB4 expression in cultured hippocampal neurons (Longart et al., 2007) (supplemental Fig. S3, available at www.jneurosci.org as supplemental material), the vast majority of GAD67immunoreactive axons are expected to originate from cells that also express ErbB4. Axons were identified by strong GAD67 immunoreactivity throughout, overall length, and the small diameter of their initial segment. In a sample of 53 interneurons in which axon identity could unambiguously be established, most (64\%/34 cells) exhibited no discernible ErbB4-IR at all (Fig. 5A-D), whereas in some cases (36\%/19 cells) ErbB4-IR extended up to four (in one case, six) cell diameters away from the soma. However, unlike in dendrites, ErbB4-IR never extended into distal regions and was low even in proximal areas. We also analyzed ErbB4-IR in hippocampal neurons expressing green fluorescent protein (GFP) fused to a mutated form of syntaphilin (SNPH $\triangle \mathrm{MT}-\mathrm{GFP}$ ) used to label axons (Kang et al., 2008). In a sample of 11 SNPHAMT-GFP-transfected and ErbB4positive cells from three independent cell preparations, ErbB4-IR was abundant in the somatodendritic compartment but absent from axons (Fig. $5 E-G$ ) [i.e., the residual fluorescence was not different from background signals observed in ErbB4-KO cells (supplemental Fig. S3, available at www.jneurosci.org as supplemental material)].

Despite the scarcity of immunoreactivity in axons, it is plausible that ErbB4 could still accumulate at presynaptic sites if the receptor is selectively retained at axon terminals. We therefore investigated possible presynaptic ErbB4 expression in DIV 14 cultured hippocampal neurons using double immunofluorescence of ErbB4 and VGAT as a marker of inhibitory presynaptic terminals (McIntire et al., 1997). Only GABAergic terminals onto ErbB4-negative (presumably pyramidal) neurons were analyzed to avoid possibly confusion with postsynaptically expressed ErbB4. As shown in Figure 5H-J, ErbB4-IR was consistently absent from VGAT-immunoreactive terminals. In fact, 
Table 1. Quantitative analysis of CCK/ErbB4 coexpression in pyramidal cell baskets in selected areas of the hippocampus and the neocortex

\begin{tabular}{lll}
\hline Brain area & CCK-innervated of total (\%) & ErbB4-IR of CCK-innervated (\%) \\
\hline CA1-3 & $78(244 / 312)$ & $0.4(1 / 244)$ \\
SUB & $48(90 / 187)$ & $8.9(8 / 90)$ \\
EC & $29(58 / 199)$ & $6.9(4 / 58)$ \\
mFC & $34(80 / 236)$ & $3.8(3 / 80)$ \\
\hline
\end{tabular}

A total of 934 pyramidal cell baskets in four neocortical and hippocampal areas was inspected for CCK and ErbB4. Data were collected from two C57BL/6 mice and one or two sections per animal and brain area. SUB, Subiculum; EC, entorhinal cortex; $\mathrm{mFC}$, medial frontal cortex.

in a random sample of 403 terminals from 24 neurons, none labeled positive for ErbB4. We sought to verify these results in situ by analyzing ErbB4-IR in GABAergic terminals in CA1 in which the anatomical relationship between presynaptic ErbB4expressing interneurons and postsynaptic ErbB4-lacking pyramidal neurons is easier to establish than in mixed hippocampal cultures. In particular, we focused on basket terminals from GABAergic interneurons that surround pyramidal cell bodies and that express either PV or CCK, as ErbB4 was reported to be present in baskets in the prefrontal cortex (Woo et al., 2007). Hippocampal sections were double-labeled for ErbB4 using mAb10 , and for PV or CCK using the respective mouse monoclonal antibodies. High-power confocal microscopy of CA1 stratum pyramidale revealed that $\mathrm{PV}$-immunoreactive baskets were generally immunonegative for ErbB4 (Fig. 6A-C). ErbB4-IR was sometimes found to outline pyramidal cell somata, but in these cases the overlay with PV was poor. Likewise, we found no evidence for ErbB4 expression in CCK-immunoreactive baskets (Fig. 6D-F). These findings were further corroborated by the general lack of ErbB4-IR in presynaptic terminals as revealed by immuno-EM (Fig. 4). However, we noticed that some CCK baskets in the subiculum expressed ErbB4 in a subset of terminals (Fig. 6G-I). These results suggest that, whereas ErbB4 expression in CA1 baskets is either very sparse or absent, there appear to be regional and interneuron type-specific differences in presynaptic ErbB4 expression. Semiquantitative analysis of CCK/ErbB4 colabeling in different cortical areas supported this notion. As shown in Table 1, ErbB4-IR in CCK-expressing baskets was virtually absent in hippocampal areas CA1-3. Of 312 pyramidal cells inspected, 244 had CCK immunoreactive baskets, but only one was also ErbB4 immunoreactive $(<1 \%)$, whereas in the subiculum, 8 of 48 CCK-immunoreactive baskets (8.9\%) were ErbB4 immunoreactive. We also assessed ErbB4-IR in CCK baskets in the neocortex and found that 3.8 and $6.9 \%$ of inspected baskets were ErbB4 immunoreactive in medial frontal and entorhinal cortices, respectively. In contrast, $\mathrm{PV}$-immunoreactive baskets were never positive for ErbB4. Notwithstanding these regional and interneuron-type specific differences, our data show that ErbB4 expression in baskets is generally sparse and, together with the lack of axonal immunoreactivity in dissociated hippocampal neurons, indicate that presynaptic accumulation is not an obligatory property of ErbB4 but likely represents a regulated process.

\section{Discussion}

The major novel findings of this study are that, within the limits of sensitivity of the immunological and molecular approaches used here, ErbB4 expression in the CA1 area of the rodent hippocampus is absent in pyramidal neurons and is restricted to the somatodendritic compartment in GABAergic interneurons. With the development of highly selective monoclonal antibodies against the receptor, and their stringent validation in protein biochemical and histological applications, including the use of negative controls from ErbB4-KO mice, this study represents the most rigorous analysis of ErbB4 receptor protein distribution reported to date. Our results have important implications as they suggest that the involvement of NRG/ErbB4 signaling in the regulation of plasticity at SC-CA1 synapses occurs at least in part via an indirect pathway, possibly including the modulation of excitatory transmission onto local ErbB4-expressing interneurons. However, as discussed in more detail below, this does not preclude the possibility that very low levels of ErbB4 receptor protein elsewhere might contribute to NRG-mediated changes in SCCA1 synaptic plasticity.

\section{ErbB4 expression in area CA1 of the hippocampus}

The monoclonal antibodies described here were developed to provide a reliable and reproducible reagent for the immunodetection of ErbB4 by a variety of different approaches. In keeping with stringency standards recently advocated by Rhodes and Trimmer (2006), we tested our antibodies rigorously for specificity in immunoblotting and immunofluorescence applications against control tissues from ErbB4-KO mice, and found mAb-10 to be particularly well suited for the analysis of cellular and subcellular expression of ErbB4 in histological sections using both conventional immunofluorescence and immuno-EM histology. Our results demonstrating ErbB4 mRNA and protein expression in hippocampal GABAergic interneurons but not pyramidal neurons is in agreement with previous in situ hybridization studies in adult rodent and nonhuman primate cortex showing scattered ErbB4 mRNA distribution in the cortex (Lai and Lemke, 1991; Gerecke et al., 2001; Fox and Kornblum, 2005; Thompson et al., 2007).

Recent reports have suggested a more even and widespread expression pattern for ErbB4 protein in the human and rat cortex including the hippocampus, based on results obtained with the C-terminal ErbB4 antibody sc-283 (Mechawar et al., 2007; Thompson et al., 2007). In these studies, multiple protein bands were observed by immunoblotting, similar to the pattern we obtained in the present study using the same antibody (Fig. 1). By direct comparison with protein extracts from ErbB4-KO mice, and through the use of three highly selective rabbit monoclonal antibodies, we demonstrated here that, in the cerebral cortex, ErbB4 migrates predominantly as a single protein of $\sim 180 \mathrm{kDa}$ representing the full-length receptor. Consistent with the notion that other bands detected with sc-283 represent cross-reacting antigens, this antibody labeled numerous cell bodies and primary dendrites in hippocampal sections of ErbB-KO mice. We therefore submit that caution needs to be exercised when interpreting immunohistological results obtained with this antibody [notwithstanding this conclusion, it is important to note that, in our hands, older lots of this antibody exhibited substantially more selectivity for ErbB4 (Garcia et al., 2000; Gerecke et al., 2001; Longart et al., 2007)]. Moreover, our results do not support the interpretation of smaller immunoreactive protein bands and of nuclear labeling of pyramidal neurons in adult rat cerebral cortex and hippocampus obtained with sc-283 as being indicative of receptor processing and nuclear translocation of the intracellular domain of ErbB4 (Mechawar et al., 2007). In fact, levels of the processed ErbB4-ICD appear to be very low in cortex and only modestly higher in the cerebellum [likely reflecting higher expression of the JM-a isoform (Elenius et al., 1997)]. Although these results do not necessarily indicate lack of receptor processing as steady-state levels of the ErbB4-ICD depend on both the rate of processing as well as the half-life of the processed fragment, they are nevertheless consistent with our previous data 
showing no ErbB4 ectodomain shedding in cultured hippocampal neurons in response to either NRG-1 or phorbol ester stimulation (Longart et al., 2007).

Although ErbB4 expression in the adult hippocampus appears to be restricted to interneurons, transient expression of ErbB4 mRNA has been noted in the developing mouse cortex and hippocampus (Fox and Kornblum, 2005). At the protein level, Yau et al. (2003) found no evidence for ErbB4 in early-born Tbr1-positive glutamatergic projection neurons at different developmental stages, and the receptor appears to be restricted to GABAergic interneurons in early and mature cultured hippocampal neurons (Yau et al., 2003; Longart et al., 2007; this study). A functional role of ErbB4 for synaptic spine maturation in CA1 pyramidal neurons was proposed based on experiments using organotypic hippocampal slice cultures from mouse neonates (Li et al., 2007), although endogenous ErbB4 expression was not directly demonstrated. Notwithstanding, recent studies using ErbB2/ErbB4 double knock-outs and NRG-1 type III heterozygous mice support an involvement of the NRG/ ErbB4 pathway in hippocampal spine morphogenesis (Chen et al., 2008; Barros et al., 2009). Our immunofluorescence and immunoelectron analyses revealed no ErbB4-IR in pyramidal cell bodies and in the vast majority of spine-like structures in the adult hippocampal CA1, whereas the receptor was readily detected at and near glutamatergic synapses on interneuron dendrites. A way to reconcile these apparent variances between receptor function and localization is to consider the possible contribution of circuit effects to altered spine densities. For example, we recently demonstrated that parvalbumin- and nNOS (neuronal nitric oxide synthase)-expressing interneurons are reduced by 24 and 27\%, respectively, in ErbB4-KO mice (Fisahn et al., 2009; Neddens and Buonanno, 2009. It is conceivable that reduced glutamatergic spine density reflects a compensatory response by pyramidal neurons to offset the resulting imbalance between excitatory and inhibitory inputs. Alternatively, ErbB4 expression might be very low (i.e., undetectable by antibody and scPCR) but functionally relevant in pyramidal neurons, or restricted to a narrow time window critical for spine maturation. Selective targeting of the ErbB4 gene to pyramidal neurons, ideally at different times during development, will be required to unequivocally resolve this question.

\section{ErbB4 and synaptic plasticity}

We previously implicated a dopaminergic pathway linking activation of NRG-1/ErbB4 signaling to the reversal of LTP at SCCA1 synapses by demonstrating that NRG-1 causes dopamine release in the dorsal hippocampus and that activation of $\mathrm{D}_{4}$ dopamine receptors is necessary and sufficient to mediate the effects of NRG-1 on LTP depotentiation (Kwon et al., 2008). Our present findings are consistent with these data as they suggest that ErbB4 does not directly regulate synaptic strength at SC-CA1 synapses but that the proximate effect of NRG-1 is to stimulate transmitter release from nearby dopaminergic afferents originating in the ventral tegmental area (VTA). Since NRG-1 depotentiates LTP in acute hippocampal slices in which the VTA afferents were separated from their cell bodies and in which the CA3 had been cut off, the effects of NRG-1 are assumed to be intrinsic to CA1 (Kwon et al., 2008). The presence of ErbB4 protein on GABAergic interneurons favors a mechanism that involves local inhibitory interneurons, since we were unable to detect the receptor in either dopaminergic afferents in the hippocampus or their somata in the VTA using a mouse monoclonal antibody (Kwon et al., 2008). Consistent with this view, NRG/ErbB4 signaling has been shown to stimulate transmitter release in GABAergic inter- neurons in the mouse prefrontal cortex (Woo et al., 2007) and hippocampus (A. Buonanno and H. Bui, unpublished observations). However, expression of low levels of ErbB receptor protein in dopaminergic cells cannot be completely excluded at this time because we (Gerecke et al., 2001), and others (Steiner et al., 1999; Thuret et al., 2004; Abe et al., 2009), have detected ErbB4 transcripts in the rodent VTA. Future experiments using the novel rabbit monoclonal ErbB4 antibodies described here may help to resolve the apparent discrepancy between protein and mRNA levels in the ventral midbrain.

\section{ErbB4 and the control of GABAergic function}

Although it is not clear to what extent NRG/ErbB4 signaling in local GABAergic interneurons contributes to the regulation of plasticity at SC-CA1 synapses, their robust expression of the receptor supports the notion that ErbB4 is involved in the regulation of interneuron and local circuit function. In CA1, the accumulation of ErbB4 at, and adjacent to, glutamatergic postsynaptic sites suggests that ErbB4 signaling modulates excitatory transmission. Consistent with this notion, electrophysiological and cell biological evidence indicates that acute NRG-1 treatment triggers the internalization of AMPA, NMDA, and $\alpha 7$ nicotinic acetylcholine receptors (Kwon et al., 2005; Gu et al., 2005; Chang and Fischbach, 2006). In contrast, we were unable to detect the receptor in axon terminals of cultured hippocampal interneurons or in CA1 baskets. Although this finding suggests a minor role for ErbB4 in directly modulating transmitter release in CA1, evidence for ErbB4 in baskets in the prefrontal cortex (Woo et al., 2007) and in a subset of CCK basket terminals in the subiculum (this study) indicate that ErbB4 could modulate presynaptic function in a region- and interneuron subtype-selective manner.

Although at first glance reduced excitatory transmission onto GABAergic interneurons would be expected to cause a reduction in inhibitory drive, experiments in the mouse prefrontal cortex (Woo et al., 2007) and the hippocampus (Buonanno and Bui, unpublished observations) show that NRG-1 actually causes an increase in the magnitude of evoked IPSCs on pyramidal neurons. However, ErbB4 signaling at the cellular level does not necessarily predict the net effect of ErbB4 actions at the local network level. Rather, additional parameters that determine spatial and temporal information processing need to be considered, such as the extent of coexpression of ErbB4 in distinct interneuron classes (Yau et al., 2003) (Neddens and Buonanno, 2009), their connectivity, and the balance between inhibition of pyramidal projection neurons and local GABAergic interneurons. Our detailed analysis of cellular and subcellular patterns of ErbB4 expression in the hippocampus (this study) (Neddens and Buonanno, 2009) should thus aid in focusing efforts to delineate the proximate effects of NRG signaling in distinct types of neurons, and to link these to the observed responses at the local circuit, systems, and behavioral levels. Moreover, the selective antibody reagents developed in this study should also be useful to (re-)map ErbB4 protein expression in other cortical and subcortical brain areas, and to characterize glutamatergic synapses on inhibitory interneurons by immunoaffinity purification of ErbB4-containing postsynaptic protein complexes.

\section{References}

Abe Y, Namba H, Zheng Y, Nawa H (2009) In situ hybridization reveals developmental regulation of ErbB1-4 mRNA expression in mouse midbrain: implication of ErbB receptors for dopaminergic neurons. Neuroscience 161:95-110. 
Barros CS, Calabrese B, Chamero P, Roberts AJ, Korzus E, Lloyd K, Stowers L, Mayford M, Halpain S, Müller U (2009) Impaired maturation of dendritic spines without disorganization of cortical cell layers in mice lacking NRG1/ErbB signaling in the central nervous system. Proc Natl Acad Sci U S A 106:4507-4512.

Bjarnadottir M, Misner DL, Haverfield-Gross S, Bruun S, Helgason VG, Stefansson H, Sigmundsson A, Firth DR, Nielsen B, Stefansdottir R, Novak TJ, Stefansson K, Gurney ME, Andresson T (2007) Neuregulin1 (NRG1) signaling through Fyn modulates NMDA receptor phosphorylation: differential synaptic function in NRG1 ${ }^{+/}$knock-outs compared with wild-type mice. J Neurosci 27:4519-4529.

Brewer GJ, Torricelli JR, Evege EK, Price PJ (1993) Optimized survival of hippocampal neurons in B27-supplemented Neurobasal, a new serumfree medium combination. J Neurosci Res 35:567-576.

Buonanno A, Fischbach GD (2001) Neuregulin and ErbB receptor signaling pathways in the nervous system. Curr Opin Neurobiol 11:287-296.

Cauli B, Audinat E, Lambolez B, Angulo MC, Ropert N, Tsuzuki K, Hestrin S, Rossier J (1997) Molecular and physiological diversity of cortical nonpyramidal cells. J Neurosci 17:3894-3906.

Chang Q, Fischbach GD (2006) An acute effect of neuregulin $1 \beta$ to suppress $\alpha 7$-containing nicotinic acetylcholine receptors in hippocampal interneurons. J Neurosci 26:11295-11303.

Chen X, Levkowitz G, Tzahar E, Karunagaran D, Lavi S, Ben-Baruch N, Leitner O, Ratzkin BJ, Bacus SS, Yarden Y (1996) An immunological approach reveals biological differences between the two NDF/heregulin receptors, ErbB-3 and ErbB-4. J Biol Chem 271:7620-7629.

Chen YJ, Johnson MA, Lieberman MD, Goodchild RE, Schobel S, Lewandowski N, Rosoklija G, Liu RC, Gingrich JA, Small S, Moore H, Dwork AJ, Talmage DA, Role LW (2008) Type III neuregulin-1 is required for normal sensorimotor gating, memory-related behaviors, and corticostriatal circuit components. J Neurosci 28:6872-6883.

Elenius K, Corfas G, Paul S, Choi CJ, Rio C, Plowman GD, Klagsbrun M (1997) A novel juxtamembrane domain isoform of HER4/ErbB4. Isoform-specific tissue distribution and differential processing in response to phorbol ester. J Biol Chem 272:26761-26768.

Fisahn A, Neddens J, Yan L, Buonanno A (2009) Neuregulin-1 modulates hippocampal gamma oscillations: implications for schizophrenia. Cereb Cortex 19:612-618.

Fox IJ, Kornblum HI (2005) Developmental profile of ErbB receptors in murine central nervous system: implications for functional interactions. J Neurosci Res 79:584-597.

Garcia RA, Vasudevan K, Buonanno A (2000) The neuregulin receptor ErbB-4 interacts with PDZ-containing proteins at neuronal synapses. Proc Natl Acad Sci U S A 97:3596-3601.

Gerecke KM, Wyss JM, Karavanova I, Buonanno A, Carroll SL (2001) ErbB transmembrane tyrosine kinase receptors are differentially expressed throughout the adult rat central nervous system. J Comp Neurol 433:86-100.

Gu Z, Jiang Q, Fu AK, Ip NY, Yan Z (2005) Regulation of NMDA receptors by neuregulin signaling in prefrontal cortex. J Neurosci 25:4974-4984.

Huang YZ, Won S, Ali DW, Wang Q, Tanowitz M, Du QS, Pelkey KA, Yang DJ, Xiong WC, Salter MW, Mei L (2000) Regulation of neuregulin signaling by PSD-95 interacting with ErbB4 at CNS synapses. Neuron 26:443-455.

Kang JS, Tian JH, Pan PY, Zald P, Li C, Deng C, Sheng ZH (2008) Docking of axonal mitochondria by syntaphilin controls their mobility and affects short-term facilitation. Cell 132:137-148.

Kaufman DL, Houser CR, Tobin AJ (1991) Two forms of the gammaaminobutyric acid synthetic enzyme glutamate decarboxylase have distinct intraneuronal distributions and cofactor interactions. J Neurochem 56:720-723.

Kwon OB, Longart M, Vullhorst D, Hoffman DA, Buonanno A (2005) Neuregulin-1 reverses long-term potentiation at CA1 hippocampal synapses. J Neurosci 25:9378-9383.

Kwon OB, Paredes D, Gonzalez CM, Neddens J, Hernandez L, Vullhorst D, Buonanno A (2008) Neuregulin-1 regulates LTP at CA1 hippocampal synapses through activation of dopamine D4 receptors. Proc Natl Acad Sci U S A 105:15587-15592.

Lai C, Lemke G (1991) An extended family of protein-tyrosine kinase genes differentially expressed in the vertebrate nervous system. Neuron 6:691-704.
Lambolez B, Audinat E, Bochet P, Crépel F, Rossier J (1992) AMPA receptor subunits expressed by single Purkinje cells. Neuron 9:247-258.

Lawrence JJ, Statland JM, Grinspan ZM, McBain CJ (2006) Cell typespecific dependence of muscarinic signalling in mouse hippocampal stratum oriens interneurones. J Physiol 570:595-610.

Li B, Woo RS, Mei L, Malinow R (2007) The neuregulin-1 receptor erbB4 controls glutamatergic synapse maturation and plasticity. Neuron 54:583-597.

Longart M, Liu Y, Karavanova I, Buonanno A (2004) Neuregulin-2 is developmentally regulated and targeted to dendrites of central neurons. J Comp Neurol 472:156-172.

Longart M, Chatani-Hinze M, Gonzalez CM, Vullhorst D, Buonanno A (2007) Regulation of ErbB-4 endocytosis by neuregulin in GABAergic hippocampal interneurons. Brain Res Bull 73:210-219.

Ma L, Huang YZ, Pitcher GM, Valtschanoff JG, Ma YH, Feng LY, Lu B, Xiong WC, Salter MW, Weinberg RJ, Mei L (2003) Ligand-dependent recruitment of the ErbB4 signaling complex into neuronal lipid rafts. J Neurosci 23:3164-3175.

McBain CJ, Fisahn A (2001) Interneurons unbound. Nat Rev Neurosci 2:11-23.

McIntire SL, Reimer RJ, Schuske K, Edwards RH, Jorgensen EM (1997) Identification and characterization of the vesicular GABA transporter. Nature 389:870-876

Mechawar N, Lacoste B, Yu WF, Srivastava LK, Quirion R (2007) Developmental profile of neuregulin receptor ErbB4 in postnatal rat cerebral cortex and hippocampus. Neuroscience 148:126-139.

Mei L, Xiong WC (2008) Neuregulin 1 in neural development, synaptic plasticity and schizophrenia. Nat Rev Neurosci 9:437-452.

Neddens J, Buonanno A (2009) Selective populations of hippocampal interneurons express ErbB4 and their number and distribution is altered in ErbB4 knockout mice. Hippocampus. Advance online publication. Retrieved August 4, 2009. doi:10.1002/hipo.20675.

Ni CY, Murphy MP, Golde TE, Carpenter G (2001) gamma-Secretase cleavage and nuclear localization of ErbB-4 receptor tyrosine kinase. Science 294:2179-2181.

Pitcher GM, Beggs S, Woo RS, Mei L, Salter MW (2008) ErbB4 is a suppressor of long-term potentiation in the adult hippocampus. Neuroreport 19:139-143.

Rhodes KJ, Trimmer JS (2006) Antibodies as valuable neuroscience research tools versus reagents of mass distraction. J Neurosci 26:8017-8020

Rio C, Buxbaum JD, Peschon JJ, Corfas G (2000) Tumor necrosis factoralpha-converting enzyme is required for cleavage of erbB4/HER4. J Biol Chem 275:10379-10387.

Singec I, Knoth R, Ditter M, Volk B, Frotscher M (2004) Neurogranin is expressed by principal cells but not interneurons in the rodent and monkey neocortex and hippocampus. J Comp Neurol 479:30-42.

Spieker-Polet H, Sethupathi P, Yam PC, Knight KL (1995) Rabbit monoclonal antibodies: generating a fusion partner to produce rabbit-rabbit hybridomas. Proc Natl Acad Sci U S A 92:9348-9352.

Steiner H, Blum M, Kitai ST, Fedi P (1999) Differential expression of ErbB3 and ErbB4 neuregulin receptors in dopamine neurons and forebrain areas of the adult rat. Exp Neurol 159:494-503.

Thompson M, Lauderdale S, Webster MJ, Chong VZ, McClintock B, Saunders R, Weickert CS (2007) Widespread expression of ErbB2, ErbB3 and ErbB4 in non-human primate brain. Brain Res 1139:95-109.

Thuret S, Alavian KN, Gassmann M, Lloyd CK, Smits SM, Smidt MP, Klein R, Dyck RH, Simon H (2004) The neuregulin receptor, ErbB4, is not required for normal development and adult maintenance of the substantia nigra pars compacta. J Neurochem 91:1302-1311.

Woo RS, Li XM, Tao Y, Carpenter-Hyland E, Huang YZ, Weber J, Neiswender H, Dong XP, Wu J, Gassmann M, Lai C, Xiong WC, Gao TM, Mei L (2007) Neuregulin-1 enhances depolarization-induced GABA release. Neuron 54:599-610.

Yau HJ, Wang HF, Lai C, Liu FC (2003) Neural development of the neuregulin receptor ErbB4 in the cerebral cortex and the hippocampus: preferential expression by interneurons tangentially migrating from the ganglionic eminences. Cereb Cortex 13:252-264.

Zhou W, Carpenter G (2000) Heregulin-dependent trafficking and cleavage of ErbB-4. J Biol Chem 275:34737-34743.

Zhu X, Lai C, Thomas S, Burden SJ (1995) Neuregulin receptors, erbB3 and erbB4, are localized at neuromuscular synapses. EMBO J 14:5842-5848. 